\title{
Gestión de la información contable: aspectos técnicos, legales y éticos
}

Gestão da informação contábil: aspectos técnicos, legais e éticos

Accounting information management: technical, legal and ethical aspects

\author{
Marinês Santana Justo SMITH (1), Bárbara FADEL (2)
}

(1) Faculdade de Filosofia e Ciências, UNESP, Av. Hygino Muzzi Filho, 737 Marília - São Paulo - Brasil, CEP: 17525-900. Centro Universitario de Franca, Uni-FACEF, Av. Major Nicácio, 2433, CEP: 14.401-135, Brasil. (2) Faculdade de Filosofia e Ciências, UNESP, Av. Hygino Muzzi Filho, 737 Marília - São Paulo - Brasil, CEP: 17525-900, bafadel@terra.com.br

\begin{abstract}
Resumen
Las decisiones tomadas en el ámbito de una empresa se reflejan en todo sistema empresarial. La empresa recibe influencia de -e influye en- varios agentes en su entorno. El eje que alimenta esa dinámica con los diversos agentes de interés en la situación económica y financiera de la empresa es la información contable financiera. Sin embargo, la divulgación de información contable de mala calidad puede perjudicar las decisiones y aún traer daños materiales a los usuarios de esa información. Así, la finalidad de ese estudio ha sido la de caracterizar los usuarios, los aspectos técnicos, legales y éticos de la información contable financiera a través de una revisión de la literatura acerca del asunto. Como resultado ha sido posible identificar la responsabilidad ética, civil y penal del profesional responsable de la elaboración y divulgación de las informaciones contables.
\end{abstract}

Palabras clave: Gestión de información. Información. Usuarios de información. Responsabilidad y ética.

\section{Introdução}

A internacionalização de mercados e dos fluxos de capitais se expandiu de forma célere e, deste duo emergiu um mercado extremamente competitivo com reflexo em todo sistema empresarial. O que direciona à compreensão da organização como

núcleo da sociedade, no sentido de que ela congrega pessoas, sustenta a economia, gera empregos, profissionaliza e especializa a atuação dos indivíduos, em suma, influencia a cultura, a educação e a própria sociedade (Valentim, 2007, p. 9).

Portanto, podemos definir a empresa como um sistema, não isolado, que recebe influência e influencia vários agentes em seu entorno, todos aqueles com interesse ou ligação de alguma forma na organização empresarial, chamados de stakeholders.

O elo que alimenta esta relação dinâmica entre a empresa e stakeholders é a informação, Qualquer postura ou atitude é construída a partir

\begin{abstract}
Decisions taken by a company are reflected across the totality of the enterprise. The company is influenced by, and influences, all the stakeholders in its operating environment. The bond that fuels the dynamic between the different interested parties in the economic and financial situation of the company is the financial accounting information. The disclosure of poor quality accounting information can affect decisions and damage users of that information. The objective of this study was to characterize users, the technical, legal and ethical aspects of the financial accounting information and to demonstrate that it is possible to identify the ethical, civil, and legal responsibilities of the professionals responsible for the developing and disclosure of accounting information.
\end{abstract}

Keywords: Information management. Information. Accounting information users. Responsibility and ethics.

da recepção da informação e seu uso. A dinâmica de construção da informação começa no interior da empresa. Para Valentim (2008) o processo de coletar, processar, gerar e disseminar novas informações perpassa por todas as atividades da empresa, desde o planejamento à execução das ações planejadas, da análise à retroalimentação desse processo, o que possibilita um processo de reaprendizagem e criação de conhecimento para o processo decisório dos administradores no âmbito interno.

E a informação, resultado desse processo, disseminada ao ambiente externo, proporciona aos diversos stakeholders o poder de utilizá-la para tomar decisões, o que define sua postura em relação à empresa e atitudes na sociedade.

Entre as informações divulgadas aos stakeholders, tem destaque, nesse estudo, a informação gerada na área contábil no âmbito das organizações empresariais, a qual é classificada como informação contábil financeira, assim denominada, pois demonstra a situação patrimonial, eco- 
nômica e financeira da empresa, ou seja, um indicador da própria situação das empresas, através das demonstrações contábeis (Marion, 2003).

Os stakeholders utilizam essas informações contábeis para tomar suas decisões de investimento e financiamento nestas organizações. Decisões de apoio ou restrição aos seus produtos, aos seus serviços ou em sua conduta de negócios. Portanto, a divulgação de informação contábil de má qualidade pode prejudicar as decisões e, ainda, trazer danos materiais aos usuários dessa informação. As questões que envolvem a informação contábil impõe responsabilidades.

Diante desse contexto, o objetivo desse estudo foi caracterizar os usuários, os aspectos técnicos, éticos e legais da informação contábil financeira. Como metodologia, foi feito um resgate de discussões literárias sobre a informação contábil financeira e seus usuários; dos aspectos técnicos, legais e éticos da informação.

\section{Aspectos técnicos e legais da informação contábil financeira}

Sob uma perspectiva sistêmica, a gestão da informação contábil não é um fim em si mesma. É um apoio imprescindível para o alcance de um objetivo mais amplo - a gestão de uma organização como um todo. Capra (2000, p. 49) destaca que no contexto sistêmico as propriedades nas partes somente podem ser compreendidas da organização do conjunto, inferindo que o pensamento sistêmico não é concentrado nos componentes básicos, mas nos princípios essenciais da gestão integral da organização empresarial. Esse é o objetivo da gestão da informação contábil - contribuir com a gestão integral.

A informação deve ser gerida com determinado propósito de ação, de forma a produzir impacto e eficiência na gestão integral da empresa. A informação para Wersig (1992, p. 233) "é o conhecimento para a ação".

No contexto empresarial, a informação tem valor comercial, entretanto para configurar conhecimento em ação, essa deve possibilitar a maximização dos processos de produção e ou viabilizar o desenvolvimento da empresa. Este tipo de informação, caracterizada como de negócios, é entendida por Dias e Belluzzo (2003) como a informação que subsidia o processo decisório do gerenciamento das empresas nos aspectos operacional, financeiro, estatístico, legal e de mercado.

A informação contábil que se apresenta como uma informação de negócios se diferencia dos outros tipos de informações por ser: a) estruturada para ser usada em decisões econômicas, b) de natureza quantitativa e financeira sendo de grande importância nas decisões sobre o que aplicar ou quanto financiar no processo de gestão estratégica do negocio (CIA, 1998).

A contabilidade como um sistema de informação e avaliação, exerce sua função comunicativa, produz relatórios com informações para controles operacionais e do cotidiano administrativo aos usuários internos. Assim como, os relatórios periódicos com informações que expressam a situação econômica e financeira da empresa aos usuários internos e externos possibilitando a esses fazerem inferências sobre as tendências. (ludícibus, Martins, Gelbcke, 2007).

Dentre as especialidades da linguagem, a contabilidade se apresenta como linguagem de negócios, como é conhecida, todavia, não tem sido homogênea no âmbito nacional e nem internacional. Isso ocorre devido à coexistência de diversos critérios de reconhecimento e mensuração de uma mesma operação na elaboração da informação contábil financeira (Weffort, 2005). Essa diferença nas práticas de elaboração da informação contábil classifica, em âmbito mundial, os sistemas contábeis em dois grandes modelos, "Anglo-Saxão e Continental", (Niyama, 2005, p. 16).

O Quadro I detalha as características desses dois modelos de sistemas de informação contábil e, destaca alguns países enquadrados em cada modelo em decorrência das características dos seus procedimentos no entorno da informação contábil.

Contudo, Niyama (2005) alerta que a classificação dos países em um modelo ou em outro, não é uma classificação definitiva e incontestável, é apenas uma forma de compreender melhor as causas das diferenças na elaboração das informações contábeis entre os diversos países.

No Brasil, a classificação como visão legalística se confirma, visto que a legislação do Imposto de Renda se destaca com imposição de limites e critérios fiscais para efeito de tributação que imprimem o aspecto fiscal à informação.

As normas da legislação fiscal têm exercido efeitos adversos sobre a teoria e os princípios contábeis que regulamentam o registro da operação administrativa. No Brasil, há empresas que efetuam contabilidade apenas para o fisco, omo observado por Carvalho, Lemos e Costa (2006, p. 11)

parece que o pensamento predominante durante décadas foi: para que investir num preparo mais acurado da posição de ativos, exigibilidades, patrimônio e lucros se a regra que prevalece é sempre a fiscal? 
Esses pensamentos e fatos limitam a evolução dos Princípios Fundamentais de Contabilidade ou dificulta a adoção prática de princípios adequados na elaboração da informação contábil em respeito ao aspecto legal dessa em relação aos demais usuários da informação, que não seja o governo. E ainda, distorce o teor da informação contábil em relação à essência dos eventos econômicos das empresas (ludícibus, Martins, Gelbcke, 2007).

\begin{tabular}{lll}
\hline \multicolumn{1}{c}{ Pontos de destaque } & \multicolumn{1}{c}{ Anglo-Saxao } & \multicolumn{1}{c}{ Continental } \\
\hline Maior fonte de captação de recursos & Sólido mercado de capitais & $\begin{array}{l}\text { Bancos e outras instituições } \\
\text { financeiras }\end{array}$ \\
\hline $\begin{array}{l}\text { Interferência governamental na } \\
\text { definição de práticas contábeis }\end{array}$ & Pouca interferência & Forte interferência \\
\hline $\begin{array}{l}\text { Principais usuários da informação } \\
\text { contábil }\end{array}$ & Investidotes & Gobernó e credores \\
\hline Estructura Legal do sistema contábil & $\begin{array}{l}\text { Common-law - visão não legalista, } \\
\text { as normas são estabelecidas pelos } \\
\text { profissionais de contabilidade }\end{array}$ & $\begin{array}{l}\text { Code-law - visão legalística, as } \\
\text { normas e regras são estabelecidas } \\
\text { pela lei através do gobernó }\end{array}$ \\
\hline Países & $\begin{array}{l}\text { Grã-Bretanha, Austrália, Nova } \\
\text { Zelândia, Estados Unidos da } \\
\text { América, Canadá, Malásia, Índia, } \\
\text { África do Sul e Cingapura }\end{array}$ & $\begin{array}{l}\text { França, Alemanha, Itália, Japão, } \\
\text { Béligica, Espanha, Europa Oriental } \\
\text { e os países da América do Sul }\end{array}$ \\
\hline
\end{tabular}

Quadro I. Sistemas de informação contábil: Modelos Anglo-Saxão e Continental

(Adaptado de Niyama, 2005)

O que enfatiza a necessidade de um conjunto de informações que demonstra a real situação econômica e financeira da empresa e que seja de acesso também aos investidores, credores e demais interessados. A informação societária também conhecida como financeira gerada para atender as necessidades informacionais dos usuários internos e externos à empresa. Essa informação tem como cerne o registro da essência econômica das operações administrativas com respaldo nos princípios fundamentais da contabilidade e na legislação das sociedades por ações com o objetivo de informar a real situação econômica e financeira da empresa.

A internacionalização dos mercados e dos fluxos de capitais demanda uma linguagem contábil financeira única. $E$ neste intento tem destaque o papel do IASB - International Accounting Standards Board, órgão que congrega representantes de vários países, responsável pela elaboração das normas internacionais de contabilidade e publicação do modelo contábil internacional, conhecido pela sigla International Financial Reporting Standards (IFRS). São mais de 100 países que já adotam e/ou permitem o uso das IFRS, entre esses, estão os países da União Européia, Austrália, Hong Kong, África do Sul, Canadá, China, Noruega, Suécia e Colômbia e muitos outros que estão empenhados no processo de convergência (Mirza, Orrell e Holt, 2008).

O Brasil também está a caminho da convergência, foram sancionadas a Lei 11.638 em 2007 e a Lei 11.941 em 2009 que alteram a legislação societária brasileira. Ainda que não configure o total alinhamento confirma um grande passo rumo a esse movimento em busca dos aspectos técnicos, legais e éticos que conferem características à informação conforme descritas no Quadro II.

Essas características são os atributos que tornam as informações úteis para os usuários. A elaboração do conjunto de informações contábeis, apresentado no Quadro III, com respaldo na Legislação Societária imprime as características apresentadas no quadro II.

Entretanto, a efetiva exigência e devida fiscalização, pela CVM - Comissão de Valores Mobiliários - da aplicação da legislação societária recaem apenas nas empresas constituídas juridicamente como Sociedades por Ações ou de grande porte. As demais empresas, de pequeno ou médio porte, constituídas como Sociedades Limitadas, têm suas informações contábeis apuradas, com certa flexibilidade, entre a Legislação Fiscal e a Societária.

Todavia, a situação da não obediência aos preceitos legais da legislação societária pode estar no fim. Isso porque, o Conselho Federal de Contabilidade (CFC), seguindo uma tendência mundial, ratificou as normas contábeis internacionais, inclusive, para as pequenas e médias empresas. 


\begin{tabular}{ll}
\hline Características & Aspectos técnicos, legais e éticos \\
\hline Qualitativas & $\begin{array}{l}\text { Compreensibilidade; relevância; confiabilidade por cumprir princípios e não normas fiscais; } \\
\text { tempestividade; compreensibilidade; Mixco prospectiva (possibilitar estudos de tendências); } \\
\text { fidelidade de representação (concordância entre a medida e o fenômeno correspondente); } \\
\text { neutralidade no sentido que a informação tenha ausência de viés. }\end{array}$ \\
\hline Transparênca & $\begin{array}{l}\text { Evidenciação ou divulgação com legitimidade; simplicidade; originalidade; revelar o que é } \\
\text { esencial. Construção da relação entre a empresa e os agentes de interesse nessa mediante } \\
\text { prática de prestação de contas. }\end{array}$ \\
\hline Comparabilidade & $\begin{array}{l}\text { Normas, para reconhecimento dos itens nas demonstrações contábeis e mensuração dos bens } \\
\text { directos obrigações, baseadas em princípios e não em regras que insira a capacidade de } \\
\text { comparar informação sobre o desempenho da organização com períodos anteriores e com } \\
\text { outras empresas }\end{array}$ \\
\hline
\end{tabular}

Quadro II. Características necessárias à informação contábil financiera

(Adaptado de Hendriksen e Van Breda, 1999; Iudícibus, Martins, Gelbcke, 2007, De Sordi, 2008).

\begin{tabular}{|c|c|}
\hline Informacões contábeis financieras & Finalidade da informação \\
\hline Balanço Patrimonial & $\begin{array}{l}\text { Informar a posição financiera e patrimonial da empresa en } \\
\text { determinada data. (aplicações e origens de recursos). }\end{array}$ \\
\hline Demonstração do resultado do exercício & $\begin{array}{c}\text { Apontar o resultado econômico da empresa gerado em } \\
\text { determinado período. (Receitas, Custos, Despesas e } \\
\text { resultado). }\end{array}$ \\
\hline Demonstrações Mutaçoes do Patrimônio Líquido & $\begin{array}{l}\text { Indicar as varioções do Patrimônio Líquido e a destinação do } \\
\text { lucro. }\end{array}$ \\
\hline Demonstração dos Fluxos de Caixa & Apontar a movimentação dos recursos monetários. \\
\hline Demonstração do valor adicionado & $\begin{array}{c}\text { Apontar o valor da riqueza gerada pela empresa e a forma de } \\
\text { distribuição }\end{array}$ \\
\hline Notas explicativas & Informações Complementares \\
\hline
\end{tabular}

Quadro III. Conjunto de informações contábeis financieras reguladas pela Legislação Societária Brasileira (Adaptado de ludícibus, Martins, Gelbcke, 2009)

Toda essa preocupação com a informação contábil financeira se justifica pela necessidade informacional dos stakeholders.

\section{Usuários da informação contábil financeira}

Em ambientes organizacionais complexos e sistêmicos, o público de interesse na saúde econômica e na forma de como esta empresa faz negócios deixa de ser apenas os gestores e governo e passa a englobar um número muito maior de pessoas e empresas. Este grupo de usuários internos e externos é conhecido como stakeholders.

Freeman e Mcvea (2000) relatam que o termo stakeholder teve sua presença marcada no campo da Administração, por ocasião de um memorando interno do Instituto de Pesquisa de Stanford (Stanford Research Institute - SRI) em 1963. O intuito inicial era nomear com essa expressão todos os grupos sem os quais não seria possível a existência da empresa e, portanto os gestores deveriam entender as preocu- pações dos stakeholders para desenvolver objetivos e ações a serem apoiados por eles. E, para esse grupo, no estudo, foram citados os acionistas, colaboradores, clientes, fornecedores, credores, governo e a sociedade. Desta forma, stakeholders pode ser qualquer grupo ou indivíduo que afeta ou é afetado pelo alcance dos objetivos da empresa.

Esses,são reais ou potenciais usuários da informação contábil financeira, retratados pela necessidade de conhecer o resultado das decisões econômicas empresariais para dar curso às suas decisões e ações particulares.

Corroborando com a relevância definida aos stakeholders Dias e Belluzzo (2003, p. 31) destacam a forte influência dos diversos usuários, os quais as autoras denominam de clientes no processo de gestão da informação.

Desta forma, torna-se necessário, não apenas identificar cada um desses clientes/usuários da informação contábil financeira, mas, também identificar quais são suas necessidades informacionais conforme apresentadas no Quadro IV. 


\begin{tabular}{ll}
\hline Usuários - Stakeholders & Necessidades informacionais \\
\hline Administradores & $\begin{array}{l}\text { Comparação entre o real o orçado e avaliação de desempenho econômico e } \\
\text { financiero para tomada de decisoes a nível operacional, de investimento e de } \\
\text { financiamento. }\end{array}$ \\
\hline Financiadores (Bancos) & Medir o endividamento para liberar créditos \\
\hline Clientes & $\begin{array}{l}\text { Medir capacidade productiva e financeira para certificar a continuidade da } \\
\text { empresa e confiar o cumprimento de prazos na entrega da mercadoria ou } \\
\text { serviço }\end{array}$ \\
\hline Colaboradores & $\begin{array}{l}\text { Conhecer o potencial financeiro e econômico da empresa para medir } \\
\text { capacidade de pagamento e benefícios e, também medir o espaço de } \\
\text { crescimento profissional ou ainda, para evitar em assumir cargos em } \\
\text { empresas com situações problemáticas }\end{array}$ \\
\hline Fornecedores (credores & Medir a capacidade e tempestividade de pagamento das empresas. \\
comerciais) & $\begin{array}{l}\text { Auditar arrecadação de impostos, mas também como dados estadísticos } \\
\text { para redimensionar a economia, estabelecer políticas fiscais e } \\
\text { regulamentadoras. }\end{array}$ \\
\hline Governo & $\begin{array}{l}\text { Medir a rentabilidade do capital investido, capacidade de pagar dividendos e, } \\
\text { ainda para subsidiar decisões de compra, manuntenção ou venda dos } \\
\text { investimentos. }\end{array}$ \\
\hline Investidores. Provedores de capital \\
de risco & $\begin{array}{l}\text { Elaborar estudos específicos em relação à produtividade para negociação de } \\
\text { reajustes de salários e estabelecimento de índice padrão para determinados } \\
\text { setores. }\end{array}$ \\
\hline Sindicatos e Associações & $\begin{array}{l}\text { Analisar as tendências e a evolução na prosperidade da empresa para a } \\
\text { sociedade a ainda medir o impacto econômico, ambiental e social da } \\
\text { atividade empresarial. }\end{array}$ \\
\hline Sociedade & \\
\hline
\end{tabular}

Quadro IV. Usuários e finalidade de uso da informação contábil financiera (Adaptado de ludícibus; Martins; Geibcke, 2007; Marion, 2003; Hendriksen; Breda, 1999

Entretanto, interessante se faz, observar que alguns usuários precisam de informações adicionais à informação contábil financeira divulgadas apenas no âmbito interno da empresas. E, o fisco que também terá necessidade de outras informações, como os ajustes que são realizados em livros auxiliares para apuração dos impostos (ludícibus, Martins, Gelbcke, 2007).

A informação contábil financeira que não expressa a realidade econômica e financeira da empresa provoca distorções na inferência do usuário da informação, e esse vai tomar decisões que resulta prejuízo em seu próprio patrimônio, o que pode provocar prejuízos em efeito dominó, ou seja, um repasse de prejuízos de stakeholder para stakeholder.

\section{Aspectos éticos na elaboração da informação contábil}

Diante da realidade que a informação contábil tem forte impacto nas decisões dos diversos stakeholders, surge a necessidade de inserir aos atributos qualitativos da informação a questão ética. A gestão da informação alinhada à questão ética está sendo uma das novas exigências do mercado, atributo que pode compor a relação das barreiras não tarifárias do merca- do, e, barrar ou dificultar a atividade das empresas que não possuem este atributo.

Essa cobrança ocorre porque a ética é inerente ao homem e, portanto, ao relacionamento social; por isso mesmo, ela é fundamental no âmbito profissional, uma vez que as responsabilidades individuais e sociais envolvem diferentes atores que se inter-relacionam (Valentim, 2004, p. 59). Neste sentido a ética profissional tem como proposição "as relações de valor que existem entre o ideal moral traçado e os diversos campos da conduta humana podem ser reunidas em um instrumento regulador". As normas de comportamento podem balizar a prática profissional no tocante à sua conduta ética em relação à sociedade em seu entorno. E "uma espécie de contrato de classe gera o Código de Ética Profissional e os órgãos fiscalização do exercício passam a controlar a execução de tal peça magna" (SÁ, 1998, p. 109).

Para os profissionais responsáveis pela elaboração das informações contábeis, a fiscalização para que se cumpra o Código de Ética Profissional do Contabilista é realizada pelos ConseIhos Federal e Regionais de Contabilidade. Esse código assume um papel relevante na inserção de qualidade nos serviços prestados e na conduta ética dos profissionais contábeis para a sociedade, sob pena de incorrer em transgres- 
são, punível pelo órgão competente. Em relação aos aspectos que devem ser observados na elaboração da informação contábil financeira Demonstrações Contábeis - é estabelecido no artigo $3^{\circ}$. do Código de Ética Profissional do Contabilista que é vedado a esse profissional, no desempenho de suas funções,

XX - elaborar demonstrações contábeis sem observância dos Princípios Fundamentais e das Normas Brasileiras de Contabilidade editadas pelo Conselho Federal de Contabilidade.

Os Princípios Fundamentais da Contabilidade tratam, entre outras, das características da informação apresentadas no Quadro II.

A ausência desses aspectos éticos, na informação contábil divulgada, representa transgressão de preceitos do Código de Ética pelo contador responsável, e, constitui infração ética sancionada. Conforme a gravidade implicará em penalidades que pode ser de advertência reservada à suspensão temporária ou perda permanente do direito de exercer a profissão de contabilista de forma legal (CFC, 1999, p. 57).

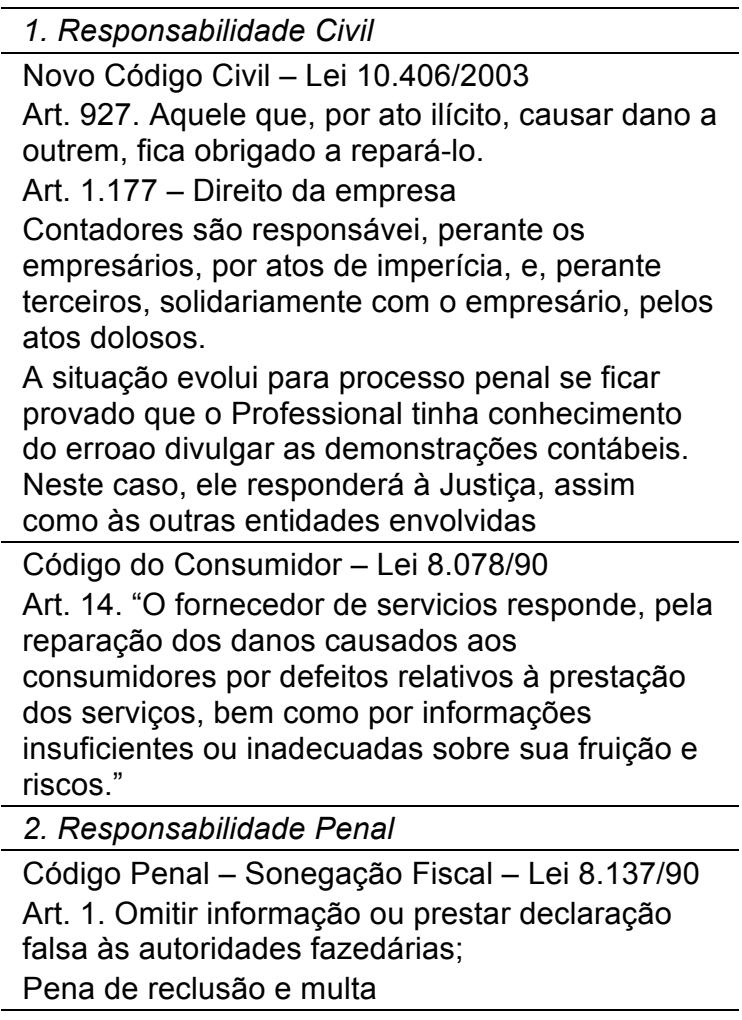

Quadro V. Responsabilidade civite e penal do contador

Contudo, a responsabilidade pela informação divulgada, não para por ai. Diante, do fato que o produto de sua competência profissional - demonstrações contábeis - refletirá nas decisões dos usuários da informação contábil e, portanto, em patrimônios particulares e/ou público, o contador pode responder por responsabilidade civil e também penal. No Quadro $V$ cita-se alguns exemplos de responsabilidade civil e penal do contador quanto à informação.

\section{Considerações finais}

Toda a diligência discutida no entorno da necessidade de princípios em detrimento das normas fiscais e jurídicas como base na elaboração das informações contábeis, se justifica diante da realidade que a empresa não é um organismo isolado. $\mathrm{E}$ como parte integrada de um sistema, recebe influência e influencia vários agentes, stakeholders, em seu entorno. O elo que alimenta essa dinâmica com os diversos agentes de interesse na situação econômica e financeira da empresa é a informação contábil financeira. Portanto, a divulgação de informação contábil de má qualidade pode prejudicar as decisões e, ainda, trazer danos materiais aos usuários dessa informação. Assim, através da revisão de literatura, dos usuários, dos aspectos técnicos, éticos e legais da informação contábil financeira, ficou demonstrado que é possível identificar a responsabilidade ética, civil e penal ao profissional responsável pela elaboração e divulgação das informações contábeis. Conclui-se que a seriedade nas questões que envolvem a informação contábil impõe responsabilidades aos gestores da informação. Essa situação desperta reflexão de que a gestão da informação contábil, no âmbito das organizações, deve garantir que a informação seja trabalhada como um recurso indispensável e estratégico no ambiente de negócios, assegurando uma gestão alinhada aos aspectos técnicos, éticos e legais da informação.

\section{Referencias}

Brasil. Lei $10.406 / 2003$, de 10 de janeiro de 2002. Novo Código Civil. http://www.planalto.gov.br/CCIVIL/ leis/2002/L10406.htm\#responsabilidadecivil (2010-0417).

Brasil. Lei № 8.078, de 11 de setembro de 1990. Código de Defesa do Consumidor. http://www.planalto.gov.br /ccivil_03/LEIS/L8078.htm (2010-04-17).

Capra, F. (2000). La Trama de La Vida: una nueva perspectiva de los sistemas vivos. Barcelona: Anagrama, 2000.

Carvalho, N. L.; Lemes, S.; Costa, F. M. (2006). Contabilidade Internacional: Aplicação das IFRS. São Paulo: Atlas, 2006.

Cia, J. N. S. (1998). Sistema de Gerenciamento de Liquidez sob a ótica da teoria das restrições: adaptação da metodologia Fleuriet. São Paulo: Escola Administração Empresas de São Paulo, FGV. 1998. Tese (Doutorado).

CFC (1999). Princípios Fundamentais de Contabilidade e ormas Brasileiras de Contabilidade; Conselho Federal de Contabilidade. Brasília: CFC. 1999. 
De Sordi, J. O. (2008). Administração da informação: Fundamentos e práticas para uma nova gestão do conhecimento. São Paulo: Saraiva, 2008.

Dias, M. M. K.; Belluzzo, R. C. B. (2003). Gestão da Informação em Ciência e Tecnologia sob a ótica do cliente. Bauru: Edusc, 2003

Freeman, R. E.; McVea, J. A. (2000). Stakeholder approach to strategic management. // Hitt, M.; Freeman, E.; Harrison, J. Handbook of strategic management. Oxford: Blackwell Publishing, 2000. 189-207.

Hendriksen, E. S.; Van Breda, Michael F. (1999). Teoria da Contabilidade. São Paulo: Atlas, 1999.

ludícibus, S; Martins, E.; Gelbcke, E. R. (2007). Manual de Contabilidade das Sociedades por ações. São Paulo: Atlas, 2007

ludícibus, S; Martins, E.; Gelbcke, E. R. (2009). Manual de Contabilidade das Sociedades por ações: Suplemento, São Paulo: Atlas, 2009.

Marion, J. C. (2003). Contabilidade Empresarial. São Paulo: Atlas, 2003

Mirza, A.; Orrel, M.; Holt, G. J. (2008). IFRS Practical Implementation Guide and Workbook. USA: Wiley, 2008.

Niyama, J. K. (2005). Contabilidade Internacional. São Paulo: Atlas, 2005
Sá, Antonio Lopes de Sá. (1998). Ética profissional. São Paulo: Atlas, 1998

Weffort, E. F. J. (2005). O Brasil e a Harmonização Contábil Internacional: Influências dos Sistemas Jurídico e Educacional, da Cultura e do Mercado. São Paulo: Atlas, 2005.

Valentim, M. L. P. (2008). Informações e conhecimento em organizações complexas. // Valentim, M. L. P. (Org.). Gestão da Informação e do Conhecimento no âmbito da Ciência da Informação. São Paulo: Polis: Cultura Acadêmica. 268 (2008) 11-26.

Valentim, M. L. P. (2007). Processo de inteligência competitiva organizacional. // Valentim, M. L. P. (Org.). Informação, conhecimento e inteligência organizacional. Marília: Fundepe Editora, 2007. 9-24.

Valentim, M. L. P. (2004). Ética profissional na área de Ciência da Informação. // Valentim, M. L. P. (Org.). Atuação profissional na área de informação. São Paulo: Polis, 2004.

Wersig, G. (1993). Information Science: the study of postmodern knowledge usage. // Information Processing \& Management. 29:2 (1993) 229-239.

Recibido: 21-04-2010. Revisado: 13-07-010.

Aceptado: 13-07-2010. 
